\title{
Helium Implantation into JSC-1A Lunar Simulant for Volatile Extraction System Testing
}

\author{
Aaron D.S. Olson \\ Fusion Technology Institute, Engineering Physics Dept., University of Wisconsin-Madison ${ }^{1}$
}

\begin{abstract}
Research is ongoing to develop an experimental volatiles extraction system that can demonstrate a heating process for releasing helium-3 $\left({ }^{3} \mathrm{He}\right)$ and other valuable lunar volatiles from lunar regolith. Beyond the Apollo and Luna program lunar samples, there is no regolith or regolith simulant implanted with solar wind volatiles that is available. A device, named the Solar Wind Implanter (SWIM), has been developed to implant helium into batches of JSC-1A simulant. It uses a voltage difference between planar electrodes to accelerate helium ions (up to the average solar- wind speed of $450 \mathrm{~km} / \mathrm{s}$ ) into a thin, falling sheet of regolith simulant. Initial implantation tests have been conducted and SWIM is being calibrated by performing tests to determine electrode current under varying operational parameters and by measuring the dose and temperature release pattern of helium in implanted samples.
\end{abstract}

\section{Introduction}

Lunar volatiles and ${ }^{3} \mathrm{He}$. The use of lunar volatiles could be pivotal for the future of human space exploration, commercial space operations, and the increasing terrestrial energy requirements. Volatiles that can be found on the Moon include hydrogen, oxygen, nitrogen, methane, carbon dioxide, carbon monoxide and helium. Propellant in the form of either hydrogen and oxygen, or methane and oxygen, can be processed from lunar soil. Water on the Moon can be electrolyzed to produce hydrogen and oxygen, or simply used for astronaut drinking water and/or plant growth (Metzger et al. 2013). The Fusion Technology Institute (FTI) of the University of WisconsinMadison has researched the acquisition and use of the lunar volatile helium-3 ( $\left.{ }^{3} \mathrm{He}\right)$ since 1985 (Wittenberg et al. 1986; Wittenberg et al. 1992). When used in a nuclear fusion reactor in combination with deuterium $\left({ }^{2} \mathrm{H}\right.$ or D) or itself, ${ }^{3} \mathrm{He}$ could produce power with much less long-lived radioactive waste than fission reactors. ${ }^{3} \mathrm{He}$ is scarce on the Earth (Wittenberg 1989). There is $<30 \mathrm{~kg}$ of the gas available through U.S. Government stockpiles (Kulcinski 2012). This is only enough for $\sim 300 \mathrm{MW}$-yr of electricity driven by fusion. Samples from Apollo 11, 12, and 14-17, along with Luna 16 and 20, indicate that there is a much larger supply of ${ }^{3} \mathrm{He}$ within reach of the Earth due to the solar wind. The solar wind, primarily composed of hydrogen $(\sim 96 \%)$ and helium-4 $\left({ }^{4} \mathrm{He}\right)$ $(\sim 4 \%)$, contains about $0.002 \%{ }^{3} \mathrm{He}$. Billions of years of solar wind impingement have deposited over 500 million tonnes of ${ }^{3} \mathrm{He}$ onto the Moon. It has been estimated that approximately one million tonnes of ${ }^{3} \mathrm{He}$ remain near the lunar surface (Wittenberg et al. 1986). Design work for robotic miners to harvest lunar ${ }^{3} \mathrm{He}$ by the FTI started in 1988 and the most recent miner design was completed in 2006 (Gajda 2006). In each miner design, excavated lunar regolith is sieved down to $<100 \mu \mathrm{m}$ particles and then heated to $700{ }^{\circ} \mathrm{C}$ in a recuperative moving bed heat pipe heat exchanger (Sviatoslavsky \& Jacobs 1988; Sviatoslavsky 1993; Gajda 2006). Two of the miner

\footnotetext{
${ }^{1}$ The work presented in this paper would not have been possible without the support of the Wisconsin Space Grant Consortium Graduate Fellowship Award and the NASA Space Technology Research Fellowship Program
} 
design iterations are illustrated in Figure 1. Heating the ${ }^{3} \mathrm{He}$ containing regolith to $700{ }^{\circ} \mathrm{C}$ has been shown to release $\approx 86 \%$ of the embedded ${ }^{3} \mathrm{He}$ (Pepin et al. 1970).
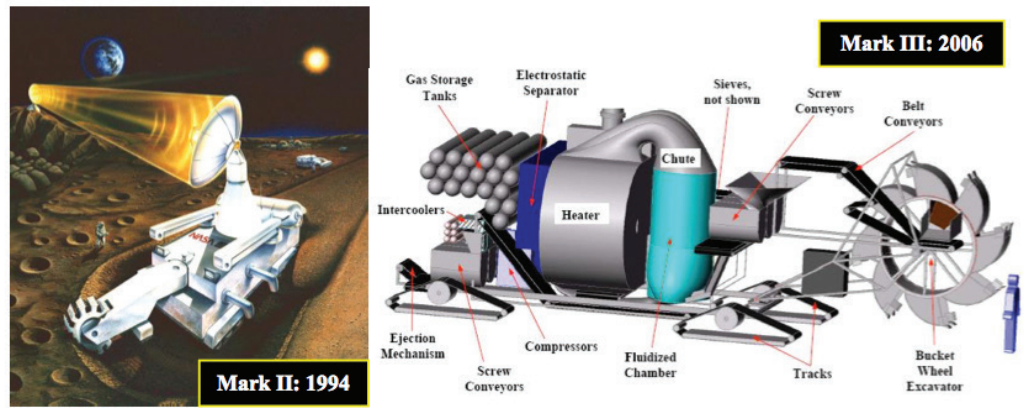

Fig. 1: Fusion Technology Institute Mark-II Lunar ${ }^{3} \mathrm{He}$ miner (Sviatoslavsky 1993) (left, illustration by J. Andrews) and Mark-III miner (Gajda 2006) (right)

Current lunar ${ }^{3} \mathrm{He}$ research. A laboratory lunar volatiles extraction system, the Helium Extraction and Acquisition Test bed (HEAT), is being developed at the FTI. The research performed on HEAT will focus on quantifying the rate of ${ }^{3} \mathrm{He}$ extraction and the thermal energy recovery within the system (Olson et al. 2014). The regolith to be processed by HEAT needs to have a known concentration of helium in order to gauge the system's performance. Other than the Apollo and Luna soil samples, there is no available regolith or regolith simulant that has been implanted to known concentrations of helium. A device referred to as the Solar Wind Implanter (SWIM) has been constructed to accomplish implantation of helium into regolith simulant.

\section{Solar Wind Implanter Objectives and Operation}

Solar wind implanter goals. The goal of the SWIM device is to implant ${ }^{4} \mathrm{He}$ and ${ }^{3} \mathrm{He}$ ions at the average solar wind speed $(\sim 450 \mathrm{~km} / \mathrm{s})$ into $1-2 \mathrm{~kg}$ batches of $<100 \mu \mathrm{m}$ JSC-1A lunar regolith simulant to a concentration of $\sim 20 \mathrm{ppb}$. JSC-1A is a mare region lunar simulant that was created for NASA (Gustafson 2007). Data from lunar samples has shown that the concentration of ${ }^{3} \mathrm{He}$ in the maria regolith is on average at least $\sim 10 \mathrm{ppb}$. The average concentration may be closer to $\sim 20 \mathrm{ppb}$. This discrepancy in volatile concentrations may be due to agitation losses in sample capture and transportation (Schmitt 2005). ${ }^{3} \mathrm{He}$ and ${ }^{4} \mathrm{He}$ have been shown to have nearly identical diffusion characteristics out of lunar regolith minerals (Kuhlman 1998). The use of primarily ${ }^{4} \mathrm{He}$ in the SWIM device, instead of the more expensive ${ }^{3} \mathrm{He}$, will suffice for most of the device's operation.

Implantation concept. The SWIM device operates within a vacuum chamber, filled with helium at pressures typically $<1$ mTorr. Helium ions are accelerated through an electrostatic potential created with the use of grounded anode grids and cathode grids negatively biased to produce $\sim 4$ $\mathrm{keV}$ ions. Negatively biased tungsten filaments ionize the helium gas in the vacuum chamber by thermionic emission. Regolith simulant flows through the accelerated ion stream and retains a fraction of the incident helium ion fluence. An illustration of this process is shown in (Fig.2). The regolith simulant flow is gravity driven and the implanted simulant is collected in a bin below the electrode grids. 

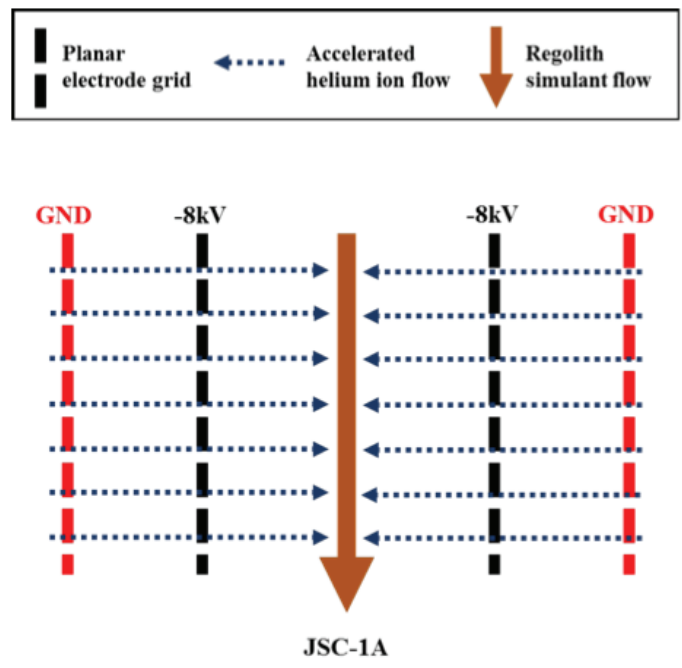

Fig. 2: Illustration of the SWIM process of regolith simulant implantation

Implantation Analysis. For a concentration, C, of helium into a mass flow rate of JSC- 1A simulant, the mass flow rate of helium to be implanted into the simulant can be described by Equation (1).

\section{$\dot{\mathrm{M}}_{\mathrm{He}}=\left(\frac{\mathrm{C}}{1-\mathrm{C}}\right) \dot{\mathrm{M}}_{\mathrm{sim}}$}

Eq. 1

Msim is the mass of simulant and its time derivative is expressed with the dot operator. The dose rate, or mass flow rate of implanted helium, can also be represented as the flow rate of implanted helium ions as shown in Equation (2).

NA is Avogadro's number and WHE is the molecular weight of whichever helium isotope being implanted. The dose rate of implanted helium ions can also be described as the product of the ion flux between the anode and cathode grids, ГHE, and the exposed surface area of the falling stream or sheet of simulant. This surface area is the same as the open area of two electrode grids, Ao, as shown in Equation (3).

The surface area that is open for the SWIM grids is a fraction of the area compared to the case where the electrodes are solid plates, as shown in Equation (4). The opaque fraction, Fo, of the grid is $\sim 0.12$. The "plate" area, Ap, is $367 \mathrm{~cm}^{2}$. The plate area is twice the product of the grid height (hGRID $=10.2 \mathrm{~cm}$ ) and grid length $($ LGRID $=18 \mathrm{~cm})$. The factor of two arises from the fact that the simulant stream is implanted from the right and left set of electrodes.

The open grid area, Ao, is $\sim 320 \mathrm{~cm}^{2}$. Reformulating Equation (3) with equations 1-4 to solve for the helium ion flux leads to Equation (5). It should be noted that Equation (5) assumes that all of the impinging ions are implanted.

$$
A_{0}=\left(1-F_{0}\right) A_{p}=2\left(1-F_{0}\right) h_{\text {grid }} L_{\text {grid }}
$$

Eq. 4
$\dot{\mathrm{N}}_{\mathrm{He}}=\dot{\mathrm{M}}_{\mathrm{He}} \mathrm{N}_{\mathrm{A}} / \mathrm{W}_{\mathrm{He}}$

Eq. 2

\section{$\dot{\mathrm{N}}_{\mathrm{He}}=\mathrm{A}_{0} \Gamma_{\mathrm{He}}$}

Eq. 3

$$
\Gamma_{\mathrm{He}}=\frac{\mathrm{N}_{\mathrm{A}} \mathrm{CM}_{\text {sim }}}{2 \mathrm{~W}_{\mathrm{He}}(1-\mathrm{C})\left(1-\mathrm{F}_{\mathrm{o}}\right) \mathrm{L}_{\text {grid }} \mathrm{h}_{\text {grid }}}
$$

Eq. 5 
The helium ion flux can be converted to an ion current density, Jimp, by using Equation (6) where the elementary charge, e, is $1.602 \times 10^{-19}$ coulombs.

$$
\mathrm{J}_{\mathrm{imp}}=\mathrm{e} \Gamma_{\mathrm{Ho}}
$$

Eq. 6

With the given SWIM system grid parameters and a simulant mass flow rate of $0.06 \mathrm{~kg} / \mathrm{s}$, the system requires a helium ion flux of $5.6 \times 10^{18} \mathrm{ions} /\left(\mathrm{m}^{2} \mathrm{~s}\right)$ or an ion current density of $0.9 \mathrm{~A} / \mathrm{m} 2$ to implant JSC-1A regolith simulant particles to a helium- 4 concentration of 20 ppb. Only a fraction of the incident helium ions are implanted. This implantation factor, Fi, needs to be empirically determined. The closer FI is to one, the more accurate Equation (5) is. For a given voltage difference between the anode and cathode grids, the ion current density is a function of the vacuum chamber pressure and the tungsten filament bias voltage, current and placement relative to the anode grid. The grid and filament parameters necessary to achieve a range of ion current densities have been empirically determined. Note that JIMP=IION/AO, where Iion is the measured current.

Experimental setup: components and operation. The primary components of the SWIM device are illustrated in (Fig. 3). These components include: a hopper/feeder system, support structure, grid electrodes and tungsten filaments needed to create and drive helium ions into the simulant, and a collection bin for the implanted simulant.

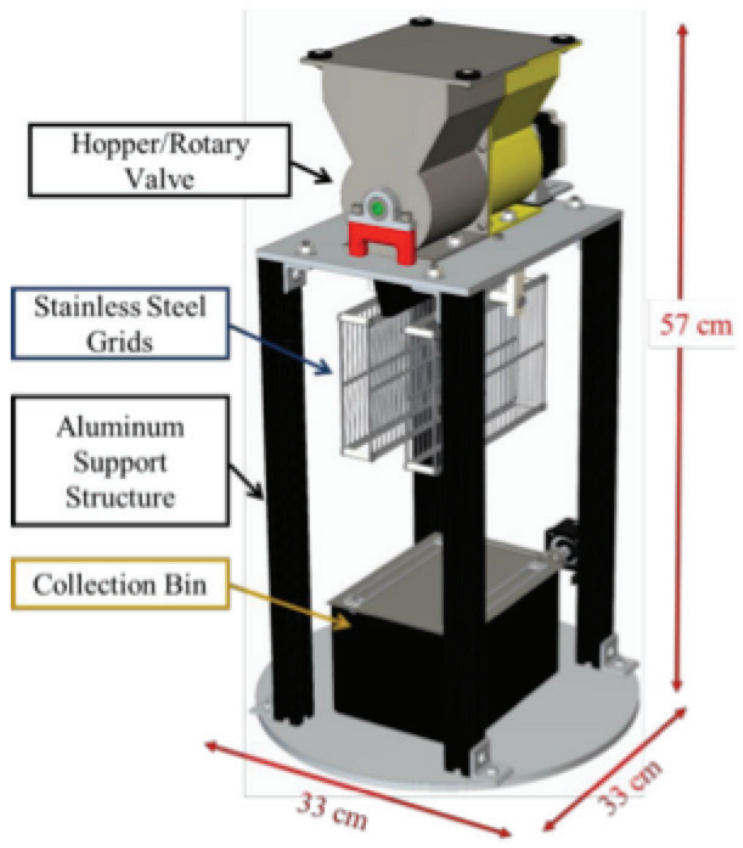

Fig. 3: Principal components of the SWIM system 


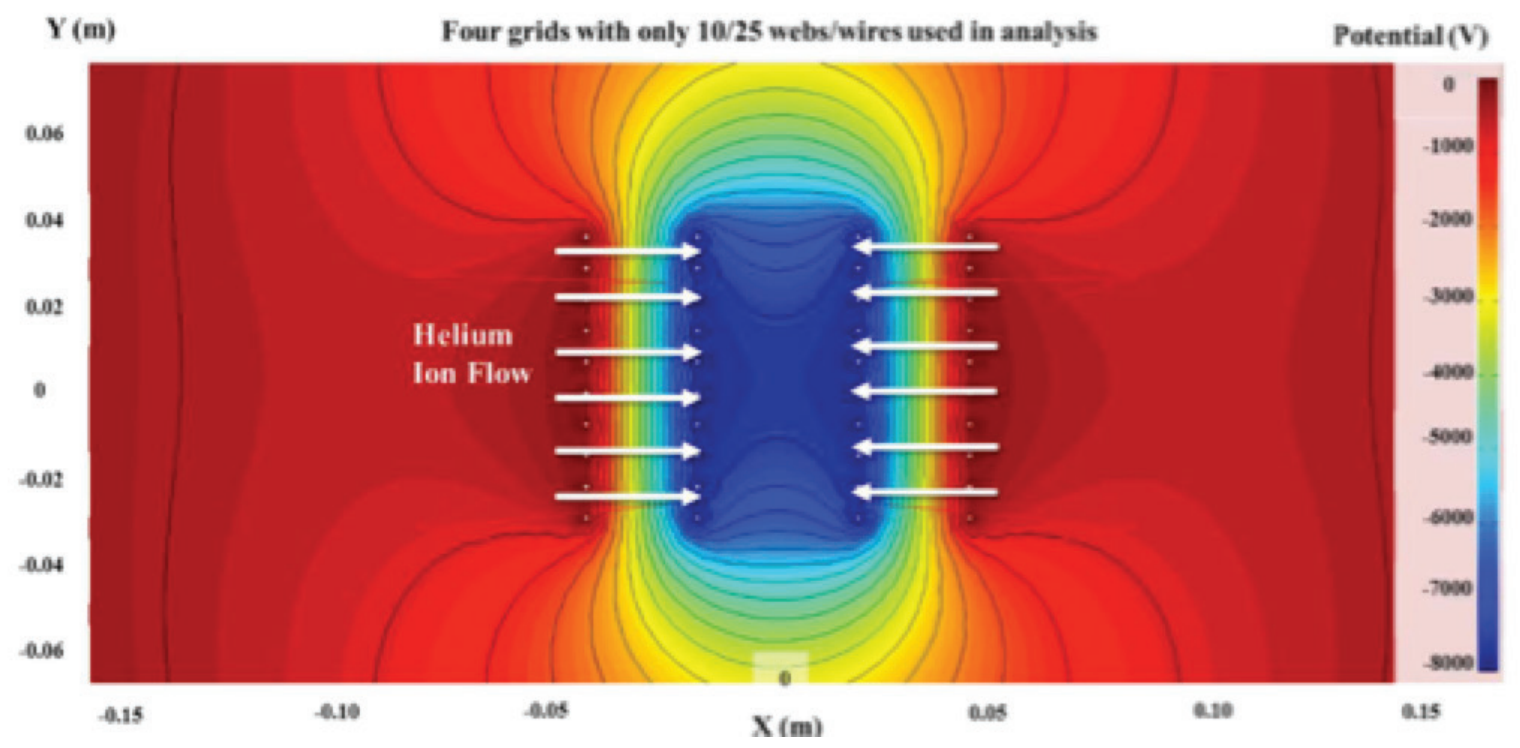

Fig. 4: Electrostatic potential contour plot for the SWIM electrode grid configuration (the arrows are superimposed to indicate that the helium ion flow is essentially uniformly into the region of simulant flow)
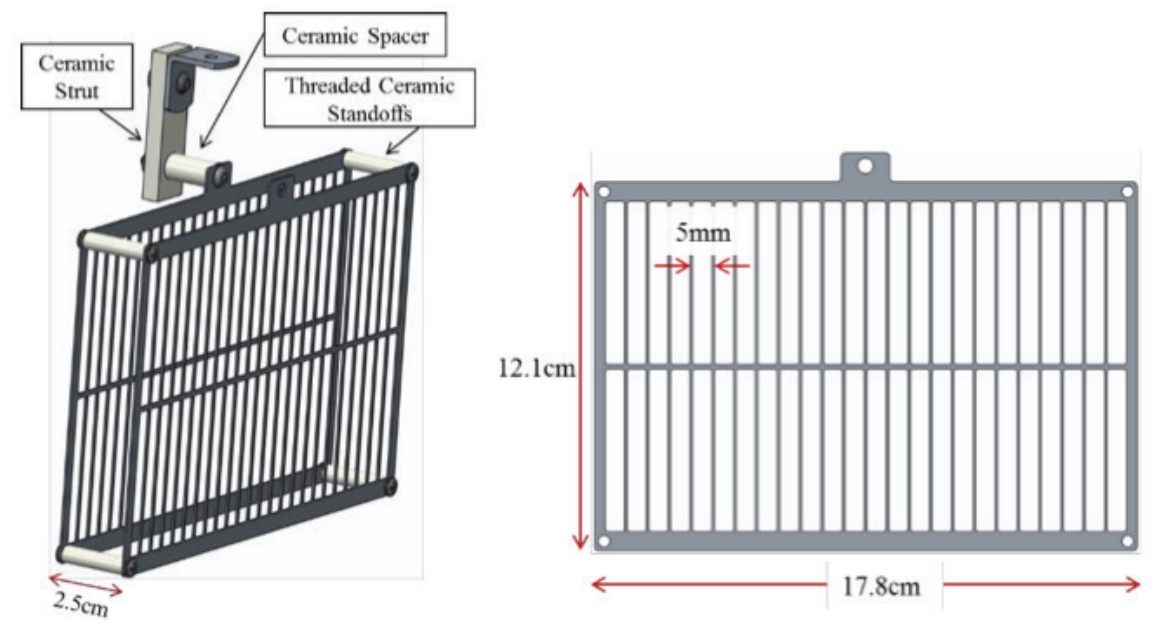

Fig.5: The SWIM grid assemblies (left), an individual anode-cathode pair and support structure (middle) and a single grid (right)

A contour plot of the predicted electrostatic potential structure produced by a model of the SWIM grid configuration (for a $-8 \mathrm{kV}$ cathode case) is shown in (Fig. 4). The plot illustrates that ionized helium ions follow the field gradient toward and into the falling simulant path. (Fig. 5) illustrates the geometry of an anode-cathode assembly and an individual electrode grid. The grids are chemically etched $0.8 \mathrm{~mm}$ thick 316 stainless steel. The simulant feeder of SWIM is $3 \mathrm{D}$ printed (casing and rotor). It can hold just over $2 \mathrm{~kg}$ of simulant while maintaining a 60 degree side inclination (from horizontal). The length of the feeder is $15.2 \mathrm{~cm}$. The feeder

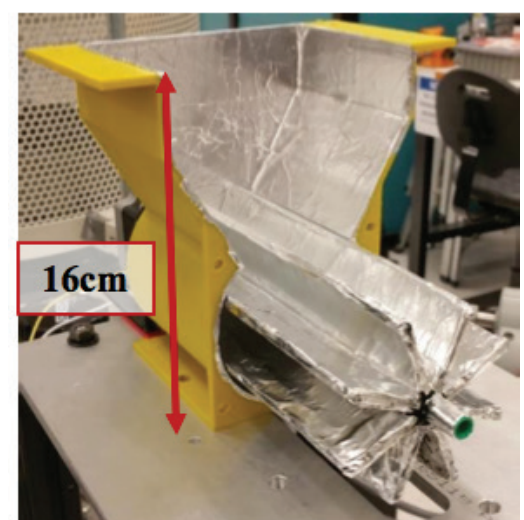

Fig. 6: Half of the hopper/feeder casing with the rotor installed. Both the casing and rotor are coated with adhesive-backed aluminum foil to reduce charging of the simulant in the feeder. 
is also sized to house a $\sim 7.5 \mathrm{~cm}$ diameter rotor with eight $0.24 \mathrm{~cm}$ thick vanes. The height of the hopper/feeder is $\sim 16 \mathrm{~cm}$. The inside surface of the feeder casing is coated with adhesive backed aluminum foil in an effort to reduce electrostatic charging of the simulant in the feeder. (Fig. 6) shows the feeder casing and rotor with the exposed aluminum foil coating.

The SWIM system has been operated in a vacuum chamber at NASA Kennedy Space Center's Swamp Works labs, but is now in an FTI laboratory vacuum chamber as shown in (Fig. 7).

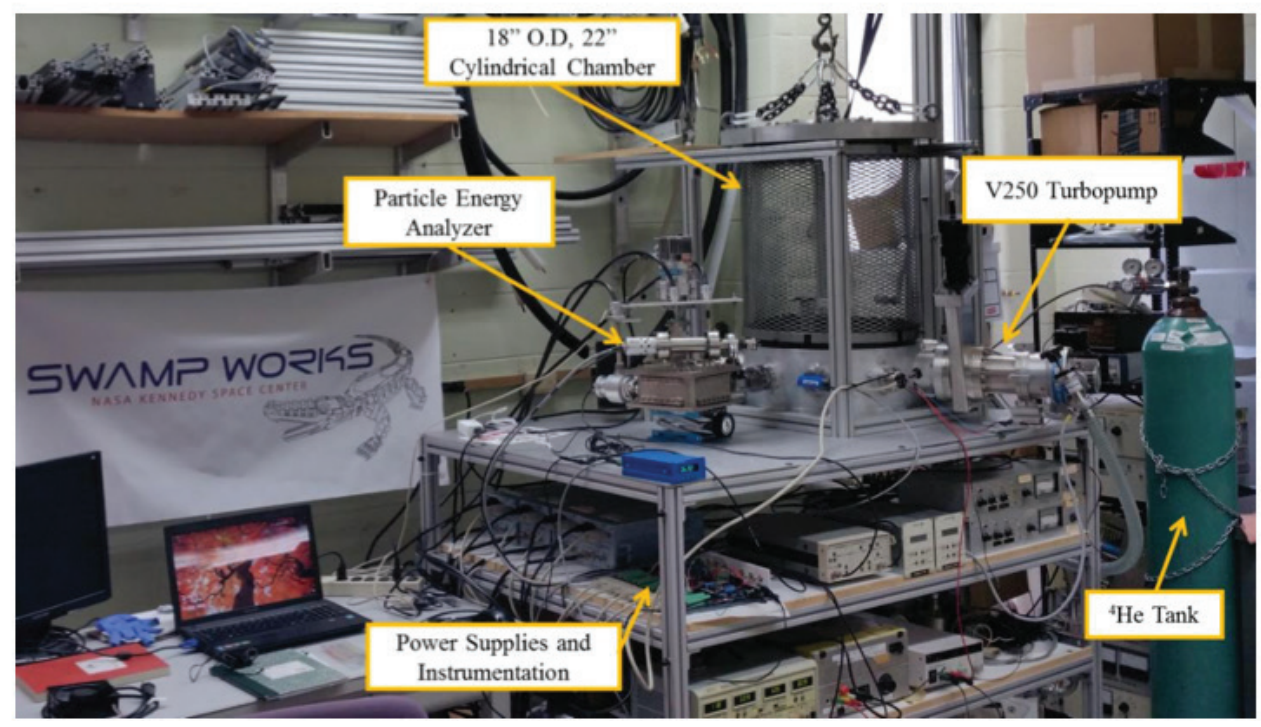

Fig. 7: SWIM vacuum chamber at the Fusion Technology Institute in Madison, WI.

The process of implanting JSC-1A simulant occurs in four steps. The first step is to fill the feeder with at most $2 \mathrm{~kg}$ of simulant before sealing the vacuum chamber. After pulling a vacuum $(<0.01 \mathrm{mTorr})$ on the chamber to reduce the presence of impurities (air), the chamber is backfilled with helium. The electrostatic potential between the anodes and cathodes is then created by setting a high voltage power supply to the desired voltage $(-8 \mathrm{kV}$ has been the nominal setting). A set of filament power supplies then negatively bias and heat two tungsten filaments (for background gas ionization). With the grid and filament power supplies on, a flux of helium ions is accelerated through the cathode grids. Lastly, simulant is dropped from the feeder in a controllable manner. (Fig. 8) illustrates the operation of the SWIM device and the path of helium ions through the grids and into the stream of falling simulant.

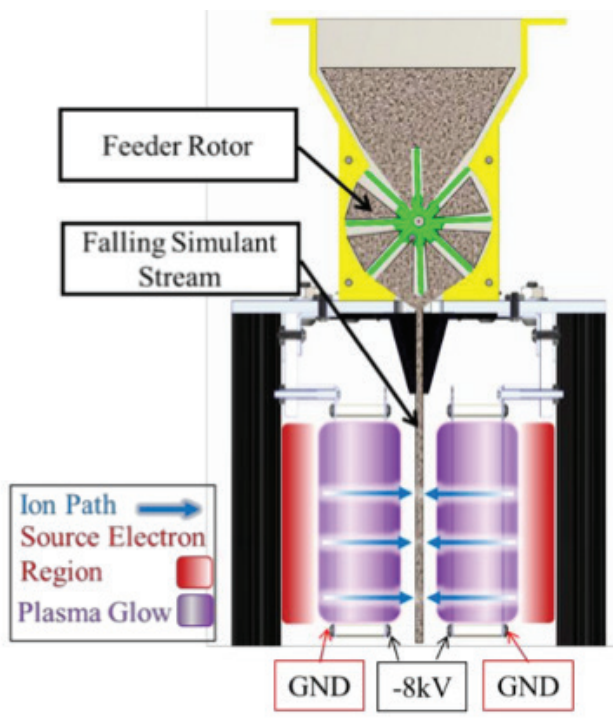

Fig. 8: Illustration of the operation of the SWIM device 


\section{Experimental Results and Future Work}

Prior to implanting simulant, testing was carried out to determine the parameters necessary to produce a given amount of current (proportional to implantation dose for a given mass flow rate of simulant). Results from this testing are shown in (Fig. 9).

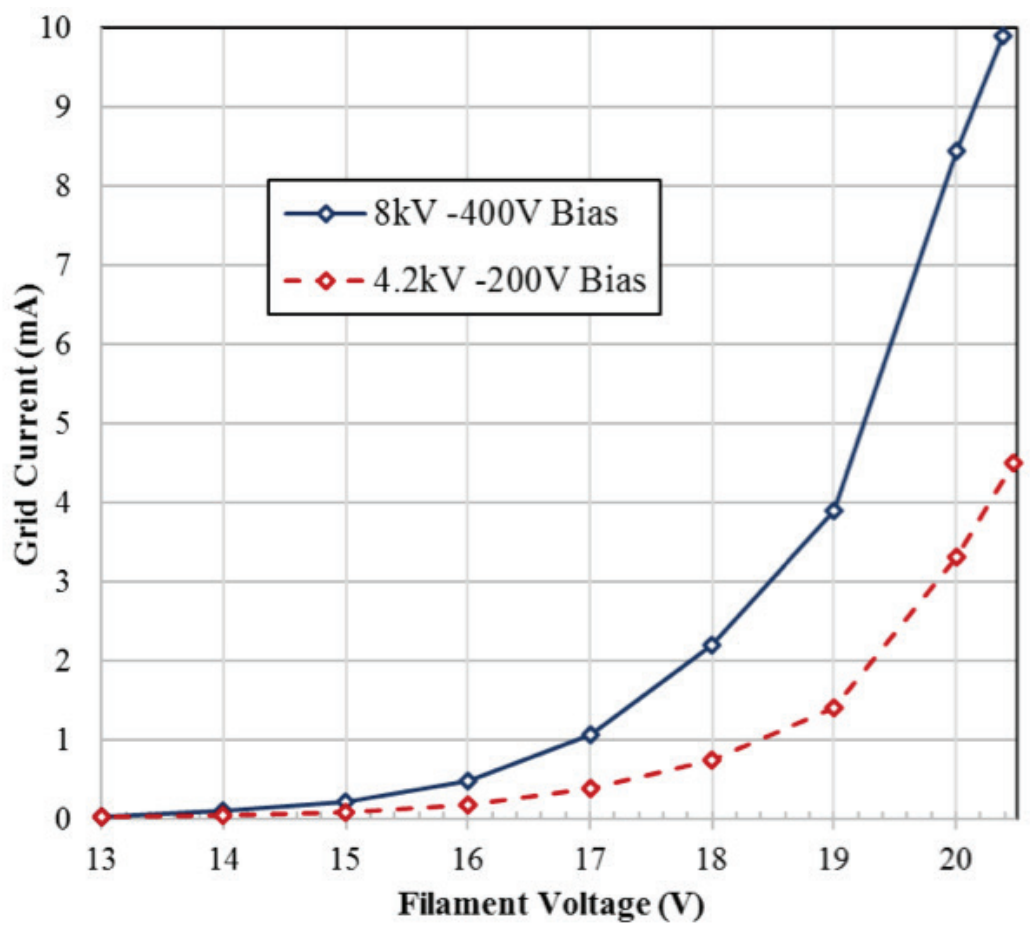

Fig. 9: Grid current vs. Filament Voltage for two cases of cathode voltage and filament bias voltage

An implantation run was completed for $72.3 \mathrm{~g}$ of $<100$ micron JSC-1A simulant. The goal was to implant to $20 \mathrm{ppb}{ }^{4} \mathrm{He}$. The vacuum chamber, grid and filament settings for the run are illustrated along with an image from inside the vacuum chamber shown in (Fig. 10). Three $\approx 100 \mu \mathrm{g}$ samples from this implantation run, along with two samples from an altered SWIM run with stationary simulant, were packaged in platinum foil sent to the a gas release testing system at the University of Minnesota (Frick et al. 1988). The samples were heated from $25^{\circ} \mathrm{C}$ up to $1510^{\circ} \mathrm{C}$ in eight steps varying from 110 to $335^{\circ} \mathrm{C}$. The released ${ }^{4} \mathrm{He}$ was measured with a calibrated mass spectrometer. The amount of ${ }^{4} \mathrm{He}$ released varied greatly among the heated samples, ranging from $0.2 \mathrm{ppb}$ to $43 \mathrm{ppb}$. The cumulative release of helium as a percentage of the total released amount is plotted against temperature in (Fig. 11). This shows that the SWIM implanted samples display a similar ${ }^{4} \mathrm{He}$ release pattern compared to the ${ }^{3} \mathrm{He}$ release pattern out of an Apollo 11 regolith sample. It also shows that there is similarity to the release patterns produced with other ${ }^{3} \mathrm{He}$ implanted lunar analog materials of the past. 


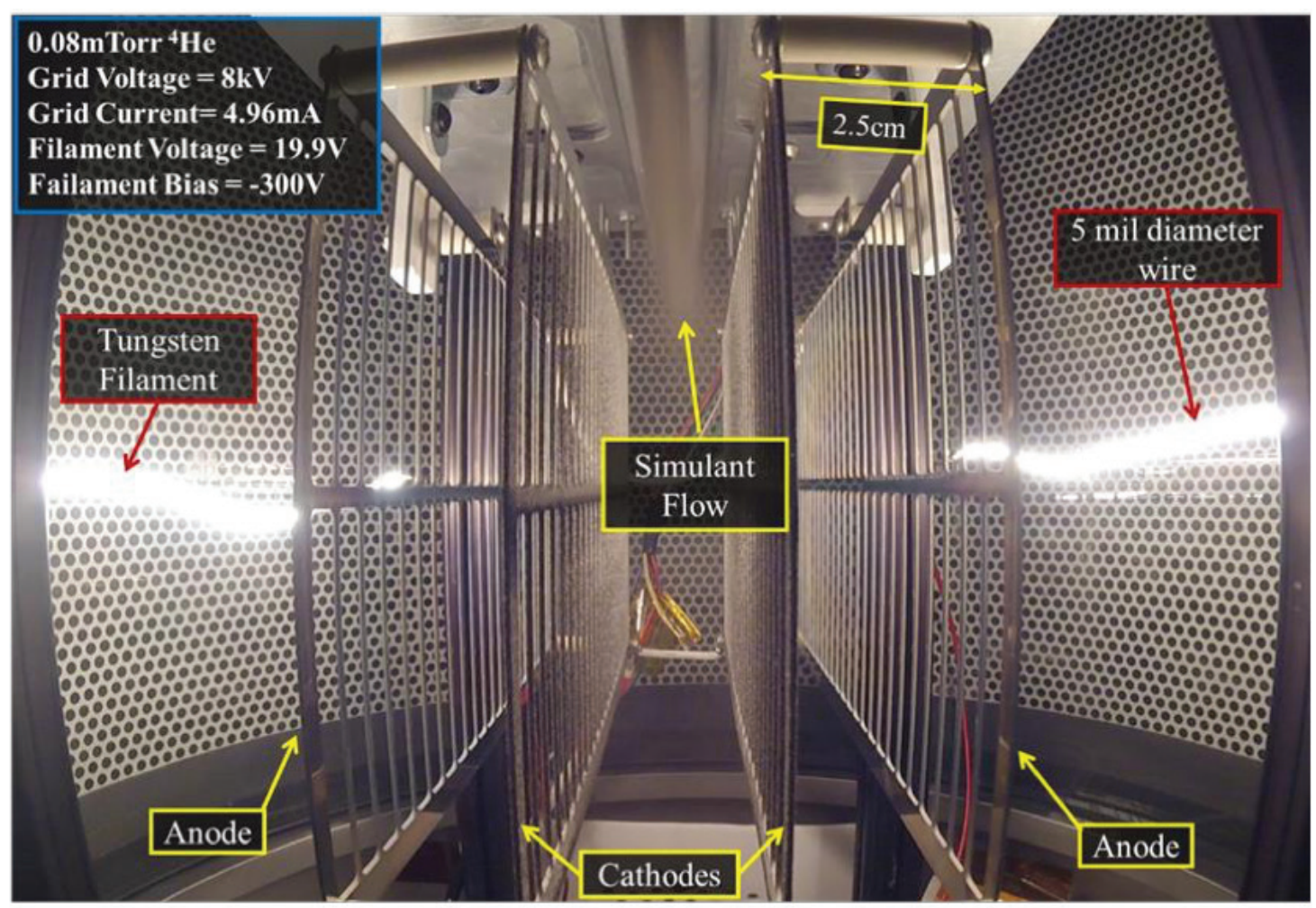

Fig. 11: ${ }^{4} \mathrm{He}$ cumulative release (\%) vs. temperature for six SWIM implanted samples of $\sim 100$ microgram compared to ${ }^{3} \mathrm{He}$ release patterns of an Apollo 11 sample and two implanted lunar analog tests.

\section{Conclusion}

The Solar Wind Implanter (SWIM) system is being developed to implant helium into lunar regolith simulant to investigate the extraction of helium for the acquisition of lunar ${ }^{3} \mathrm{He}$ for fusion energy and lunar volatiles for life support and other applications. The operation, setup and early test results of the system have been shared. Continued testing will allow the system to be calibrated to produce simulant repeatedly with desired implantation doses.

\section{Acknowledgements}

- Wisconsin Space Grant Consortium Graduate Fellowship Program

- $\quad$ NASA Space Technology Fellowship Program

- $\quad$ Prof. Gerald L. Kulcinski, University of Wisconsin-Madison, Engineering Physics Dept.

- $\quad$ Prof. John F. Santarius, University of Wisconsin-Madison, Engineering Physics Dept.

- $\quad$ Prof. Robert Pepin and Dennis Schlutter, University of Minnesota, Physics Dept.

- Dr. James Mantovani, NASA Kennedy Space Center Swamp Works Labs

References

Frick, U., Becker, R. \& Pepin, R.O., 1988. Solar Wind Record in Lunar Regolith. In Lunar and Planetary Science Conference. Houston, TX: Cambridge University Press/ Lunar and Planetary Institute, pp. 87-120. Available at: http://adsabs.harvard.edu/abs/1988LPSC...18...87F.

Gajda, M., 2006. A Lunar Volatiles Miner. University of Wisconsin-Madison, M.S. Thesis. Available at: http://fti.neep.wisc.edu/pdf/fdm1304.pdf.

Gustafson, M., 2007. Characterization Summary of JSC-1A Bulk Lunar Mare Regolith Simulant. Orbital Technologies Corporation Report - http://isru.msfc.nasa.gov/sim_docs.html.

Kuhlman, K.R., 1998. Trapping and Diffusion of Helium in Lunar Materials. University of Wisconsin-Madison Ph.D. Thesis. Available at: http://fti.neep.wisc.edu/pdf/fdm1095.pdf.

Kulcinski, G.L., 2012. Fusion Fuel Resources. In UW-Madison, NEEP-536 Course Lecture 6, Sept. 20, 2012. p. 20. 
Metzger, P.T. et al., 2013. Affordable, Rapid Bootstrapping of the Space Industry and Solar System Civilization. Journal of Aerospace Engineering, 26(1), pp.18-29. Available at: http://ascelibrary.org/doi/abs/10.1061/(ASCE)AS.19435525.0000236 [Accessed January 23, 2013].

Olson, A.D.S., Santarius, J.F. \& Kulcinski, G.L., 2014. Design of a Lunar Solar Wind Volatiles Extraction System. In AIAA SPACE 2014 Conference and Exposition. Available at: http://arc.aiaa.org/doi/abs/10.2514/6.2014-4234 [Accessed August 25, 2014].

Pepin, R.O. et al., 1970. Rare Gases in Apollo 11 Lunar Material. In Proceedings of the Apollo 11 Lunar Science Conference. pp $1435-1454$.

Schmitt, H.H., 2005. Return to the Moon. In Return to the Moon. Praxis, p. 89.

Sviatoslavsky, I.N., 1993. The Challenge of Mining He-3 on the Lunar Surface: How All the Parts Fit Together. In Space 94, The 4th International Conference and Exposition on Engineering, Construction and Operations in Space, and The Conference and Exposition/Demonstration on Robotics for Challenging Environments, February 26 - March 3, 1994, Albuquerque NM Also: WCS.

Sviatoslavsky, I.N. \& Jacobs, M.K., 1988. Mobile Helium-3 Mining and Extraction System and Its Benefits Toward Lunar Base Self-Sufficiency. In Wisconsin Center for Space Automation and Robotics Technical Report (WCSAR-TR) AR3-8808-1.

Wittenberg, L.J. et al., 1992. A Review of Helium-3 Resources and Acquisition for Use as Fusion Fuel. Fusion Technology, 21, pp.2230-2253.

Wittenberg, L.J., 1989. Terrestrial Sources of Helium-3 Fusion Fuel- A Trip to the Center of the Earth. Fusion Technology, 15(1108). Available at: http://fti.neep.wisc.edu/pdf/fdm769.pdf.

Wittenberg, L.J., Santarius, J.F. \& Kulcinski, G.L., 1986. Lunar Source of 3He For Commercial Fusion Power. Fusion Technology, 10, pp.167-178. 